\title{
Accuracy of Core Needle Biopsy Versus Fine Needle Aspiration Cytology for Diagnosing Salivary Gland Tumors
}

In Hye Song · Joon Seon Song Chang Ohk Sung $\cdot$ Jong-Lyel Roh ${ }^{1}$ Seung-Ho Choi ${ }^{1}$ · Soon Yuhl Nam ${ }^{1}$ Sang Yoon $\mathrm{Kim}^{1} \cdot$ Jeong Hyun Lee ${ }^{2}$ Jung Hwan Baek ${ }^{2}$ Kyung-Ja Cho

Departments of Pathology, ${ }^{1}$ Otorhinolaryngology, and ${ }^{2}$ Radiology, Asan Medical Center, University of Ulsan College of Medicine, Seoul, Korea

Received: October 24, 2014

Revised: December 16, 2014

Accepted: January 3, 2015

\section{Corresponding Author}

Kyung-Ja Cho, M.D.

Department of Pathology, Asan Medical Center,

University of Ulsan College of Medicine, 88

Olympic-ro 43-gil, Songpa-gu, Seoul 138-736,

Korea

Tel: $+82-2-3010-4545$

Fax: +82-2-472-7898

E-mail: kjc@amc.seoul.kr
Background: Core needle biopsy is a relatively new technique used to diagnose salivary gland lesions, and its role in comparison with fine needle aspiration cytology needs to be refined. Methods: We compared the results of 228 ultrasound-guided core needle biopsy and 371 fine needle aspiration procedures performed on major salivary gland tumors with their postoperative histological diagnoses. Results: Core needle biopsy resulted in significantly higher sensitivity and more accurate tumor subtyping, especially for malignant tumors, than fine needle aspiration. No patient developed major complications after core needle biopsy. Conclusions: We recommend ultrasoundguided core needle biopsy as the primary diagnostic tool for the preoperative evaluation of patients with salivary gland lesions, especially when malignancy is suspected.

Key Words: Salivary gland neoplasms; Biopsy, large-core needle; Biopsy, fine-needle; Parotid gland; Submandibular gland
In recent decades, fine needle aspiration cytology (FNAC) has been established as an efficient diagnostic tool for superficial masses, including salivary gland lesions. FNAC is technically simple, safe, fast, and cost-effective. However, FNAC traditionally demonstrates relatively low sensitivity in comparison with its high specificity for diagnosing salivary gland tumors. According to a previous meta-analysis by Schmidt et al., ${ }^{1}$ the average sensitivity and specificity determined in 6,169 cases were $80 \%$ and $97 \%$, respectively. Recent studies report that the sensitivity and specificity of FNAC range between $64 \%-90 \%$ and $86 \%-100 \%$, respectively. ${ }^{2-8}$ The low sensitivity of FNAC can be attributed to several factors, but is primarily due to the difficulty of diagnosing low-grade carcinomas by cellular morphology alone.

Core needle biopsy $(\mathrm{CNB})$ is a relatively new technique for diagnosing salivary gland lesions. Since intact tissue cores can be retrieved using ultrasound-guided $\mathrm{CNB}$, improved specimen adequacy is expected. The sensitivity and specificity of sal- ivary gland CNB are reportedly 92\%-94\% and 99\%-100\%, respectively. ${ }^{9-12}$ Preoperative evaluation of salivary gland lesions should provide the clinicians with a treatment plan including the type and extent of surgical intervention needed. For this purpose, differentiating benign from malignant tumors is crucial, and moreover, information on the grade and specific type of the tumor will further aid in the choice of therapeutic procedures.

With the aim of establishing the most accurate diagnostic tool as new techniques emerge, we compared the diagnostic accuracy and accurate tumor subtyping rates of CNB and FNAC performed for the preoperative evaluation of salivary gland tumors.

\section{MATERIALS AND METHODS}

Between July 2008 and June 2013, 708 tumors in the major salivary glands were surgically resected from 705 patients at Asan Medical Center in Seoul, Korea. Of these 708 cases, 562 cases 
had undergone in-house preoperative FNAC and/or ultrasoundguided CNB (US-CNB) procedures 1-3 times previously. The FNAC procedures were performed by pathologists on 371 occasions, using traditional methods with 23-gauge syringes. Two hundred and twenty-eight $\mathrm{CNB}$ procedures were performed by radiologists under ultrasound guidance, using a 1.1- or 1.6-cm excursion, 18-gauge, double-action, spring-activated needle (TSK Ace-cut, Create Medic, Yokohama, Japan) after administering local anesthesia with $1 \%$ lidocaine. Of these, 33 cases had undergone FNAC followed by US-CNB. No patients developed immediate or delayed complications after the procedure. We compared the diagnoses determined by preoperative FNAC without image guidance and US-CNB with the postoperative histological diagnoses. In addition, specimen adequacy, sensitivity, specificity, positive predictive value (PPV), negative predictive value (NPV), numbers of false-negative and -positive cases, and accurate tumor subtyping rate were analyzed. Tumor subtyping was considered accurate when one exact tumor type was diagnosed, favored, suggested, or suspected. The $t$ test was used to evaluate differences in continuous data. The chi-squared test was used to assess the associations between categorical groups. The two-group proportion test was used to compare FNAC and $\mathrm{CNB}$. All tests were two-sided, and $\mathrm{p}<.05$ was considered statistically significant. Statistical analyses were performed using Stata/IC statistical software ver. 12 (StataCorp. Ltd., College Station, TX, USA).

\section{RESULTS}

\section{Characteristics of the examined cases}

The locations of the 562 surgical cases included parotid gland ( $\mathrm{n}=472$ ), submandibular gland ( $\mathrm{n}=88$ ), and sublingual gland $(\mathrm{n}=2)$. Histologic diagnoses included 103 malignant and 459 benign tumors. Malignant tumors included 21 mucoepidermoid carcinomas, 17 salivary duct carcinomas, 17 carcinoma ex pleomorphic adenomas, 12 adenoid cystic carcinomas, 10 acinic cell carcinomas, 7 basal cell adenocarcinomas, 5 adenocarcinomas not otherwise specified, 3 epithelial-myoepithelial carcinomas, 3 squamous cell carcinomas, 2 oncocytic carcinomas, 1 cystadenocarcinoma, 3 malignant lymphomas, 1 rhabdomyosarcoma, and 1 undifferentiated pleomorphic sarcoma. Benign tumors included 305 pleomorphic adenomas, 96 Warthin tumors, 37 basal cell adenomas, 7 myoepitheliomas, 3 oncocytomas, 1 lymphadenoma, 5 neurogenic tumors ( 4 schwannomas and 1 neurofibroma), 3 vascular tumors (2 hemangiomas and 1 lymphangioma), and 2 lipomas.
When the general characteristics of the CNB and FNAC groups were compared to exclude selection bias, the proportion of malignancy, location, laterality, and multiplicity were not significantly different between the two groups (Table 1). One significant difference was the tumor size. The average size of tumors in the FNAC group was bigger than that in the CNB group ( $\mathrm{p}=.006$ ), which can be explained by the fact that generally patients with larger palpable tumors are sent to the Pathology Department for FNAC.

\section{Specimen adequacy}

Regarding the specimen adequacy of the $228 \mathrm{CNB}$ specimens and 371 FNAC samples, the unsatisfactory rate tended to be lower following CNB (2.6\%) than FNAC (6.2\%) (Table 2). A total of 33 cases underwent $\mathrm{CNB}$ after FNAC. Adenoid cystic carcinoma, salivary duct carcinoma, and oncocytoma showed high rates for multiple diagnostic procedures $(3 / 12,3 / 17$, and $1 / 3$, respectively).

\section{Accuracy}

The sensitivity of detecting malignant tumors using the CNB method was significantly higher (88.2\%) than that with FNAC (58.2\%) ( $\mathrm{p}=.006)$ (Table 3). The specificity, PPV, and NPV of $\mathrm{CNB}$ were slightly higher than those of FNAC, without significant differences.

\section{False-negative and -positive cases}

A total of 29 false-negative cases and 5 false-positive cases are listed in Table 4. False-negative results by CNB were restricted to cases of basal cell adenocarcinoma, carcinoma ex pleomorphic adenoma, and epithelial-myoepithelial carcinoma, while falsenegative results by FNAC were found in a wide range of tumors

Table 1. General characteristics of salivary gland tumors according to $\mathrm{CNB}$ and FNAC

\begin{tabular}{llccc}
\hline Characteristic & & $\begin{array}{c}\text { CNB } \\
(n=228)\end{array}$ & $\begin{array}{c}\text { FNAC } \\
(n=371)\end{array}$ & p-value \\
\hline Malignant:benign tumor & & $54: 174$ & $62: 309$ & .479 \\
Size (mean \pm SD, cm) & & $2.57 \pm 1.22$ & $2.85 \pm 1.21$ & .006 \\
Site & Parotid & $171(75.0)$ & $329(88.7)$ & .150 \\
& SMG & $56(24.6)$ & $40(10.8)$ & \\
Laterality & SLG & $1(0.4)$ & $2(0.5)$ & \\
& Left & $126(55.2)$ & $193(52.0)$ & .687 \\
Multiplicity & Right & $100(43.9)$ & $175(47.2)$ & \\
& Bilateral & $2(0.9)$ & $3(0.8)$ & \\
\hline
\end{tabular}

Values are presented as number (\%) unless otherwise indicated. $\mathrm{CNB}$, core needle biopsy; FNAC, fine needle aspiration cytology; SD, standard deviation; SMG, submandibular gland; SLG, sublingual gland. 
Table 2. Unsatisfactory rates and repeated diagnostic procedure rates of salivary gland tumors according to histologic diagnoses

\begin{tabular}{|c|c|c|c|c|}
\hline \multirow{2}{*}{$\begin{array}{l}\text { Histologic } \\
\text { diagnoses }\end{array}$} & & \multicolumn{2}{|c|}{ Unsatisfactory rates } & \multirow{2}{*}{$\begin{array}{l}\text { Rates for multi- } \\
\text { ple procedures }\end{array}$} \\
\hline & & CNB & FNAC & \\
\hline \multirow[t]{14}{*}{ Malignancy } & ACC & 0/9 & $1 / 6$ & $3 / 12$ \\
\hline & AciCC & $1 / 4$ & $0 / 7$ & $1 / 10$ \\
\hline & ANOS & $0 / 2$ & $1 / 3$ & $0 / 5$ \\
\hline & BADC & $0 / 2$ & $1 / 5$ & $0 / 7$ \\
\hline & CPA & $0 / 5$ & $1 / 13$ & $1 / 17$ \\
\hline & CystADC & - & $1 / 2$ & $0 / 1$ \\
\hline & EMC & $0 / 2$ & $0 / 2$ & $1 / 3$ \\
\hline & MEC & $1 / 15$ & $1 / 7$ & $1 / 21$ \\
\hline & OC & - & $0 / 2$ & $0 / 2$ \\
\hline & SCC & $1 / 3$ & $0 / 1$ & $1 / 3$ \\
\hline & SDC & $0 / 10$ & $1 / 10$ & $3 / 17$ \\
\hline & $\mathrm{ML}$ & $0 / 1$ & $0 / 2$ & $0 / 3$ \\
\hline & RMS & $0 / 1$ & - & $0 / 1$ \\
\hline & UPS & - & $0 / 1$ & $0 / 1$ \\
\hline Subtotal & & $3 / 54(5.6)$ & 7/62 (11.3) & \\
\hline \multirow[t]{9}{*}{ Benign } & PA & $1 / 117$ & $10 / 199$ & $11 / 305$ \\
\hline & WT & $2 / 33$ & $3 / 70$ & $6 / 96$ \\
\hline & BA & $0 / 16$ & $0 / 24$ & $2 / 37$ \\
\hline & LA & $0 / 1$ & - & $0 / 1$ \\
\hline & ME & $0 / 2$ & $0 / 6$ & $1 / 7$ \\
\hline & Oncocytoma & $0 / 2$ & $1 / 2$ & $1 / 3$ \\
\hline & NT & $0 / 3$ & $1 / 3$ & $1 / 5$ \\
\hline & VT & - & $0 / 3$ & $0 / 3$ \\
\hline & Lipoma & - & $1 / 2$ & $0 / 2$ \\
\hline Subtotal & & $3 / 174(1.7)$ & $16 / 309(5.2)$ & \\
\hline Total & & $6 / 228$ & 23/371 (6.2) & \\
\hline
\end{tabular}

Values in parentheses are presented as percentage.

CNB, core needle biopsy; FNAC, fine needle aspiration cytology; ACC, adenoid cystic carcinoma; AciCC, acinic cell carcinoma; ANOS, adenocarcinoma, not otherwise specified; BADC, basal cell adenocarcinoma; CPA, carcinoma ex pleomorphic adenoma; CystADC, cystadenocarcinoma; EMC, epithelial-myoepithelial carcinoma; MEC, mucoepidermoid carcinoma; OC, oncocytic carcinoma; SCC, squamous cell carcinoma; SDC, salivary duct carcinoma; ML, malignant lymphoma; RMS, rhabdomyosarcoma; UPS, undifferentiated pleomorphic sarcoma; PA, pleomorphic adenoma; WT, Warthin tumor; BA, basal cell adenoma; LA, lymphadenoma; ME, myoepithelioma; NT, neurogenic tumor; VT, vascular tumor. including adenoid cystic carcinoma, acinic cell carcinoma, adenocarcinoma not otherwise specified, mucoepidermoid carcinoma, oncocytic carcinoma, and malignant lymphoma (Fig. 1). No high-grade carcinomas (e.g., salivary duct carcinoma) were diagnosed as false-negatives by either method. False-positive results from neither method exhibited specific patterns; they might be the result of misinterpretation of pathologic findings, with or without artifacts.

\section{Accurate tumor subtyping}

The accurate tumor subtyping rates of the salivary gland tumors were significantly higher with $\mathrm{CNB}(88.3 \%)$ than with FNAC $(70.7 \%)(\mathrm{p}<.001)$ (Table 5). Immunohistochemical studies for tumor subtyping were performed in $11 \mathrm{CNB}$ samples: CD117 in adenoid cystic carcinoma; smooth muscle actin, calponin, and p63 in pleomorphic adenoma; and S100 protein in

Table 3. Accuracy of preoperative CNB and FNAC for diagnosing salivary gland tumors

\begin{tabular}{lccc}
\hline Characteristic & CNB & FNAC & $p$-value \\
\hline Total No. of cases & 228 & 371 & - \\
No. of adequate specimens, $n(\%)$ & $222(97.4)$ & $348(93.8)$ & - \\
No. of unsatisfactory specimens, $n(\%)$ & $6(2.6)$ & $23(6.2)$ & .078 \\
No. of adequate malignant cases & 51 & 55 & - \\
No. of preop. Dx as malignancy & 45 & 32 & - \\
No. of adequate benign cases & 171 & 293 & - \\
No. of preop. Dx as benign & 170 & 289 & - \\
Sensitivity (\%) & 88.20 & 58.20 & .006 \\
Specificity (\%) & 99.40 & 98.60 & .742 \\
Positive predictive value (\%) & 97.80 & 88.90 & .253 \\
Negative predictive value (\%) & 96.60 & 92.60 & .121 \\
\hline
\end{tabular}

CNB, core needle biopsy; FNAC, fine needle aspiration cytology; preop., preoperative; Dx, diagnosis.

Table 4. False-negative and -positive results determined by preoperative CNB and FNAC

\begin{tabular}{lcl}
\hline Histologic diagnoses & CNB & \multicolumn{1}{c}{ FNAC } \\
\hline Malignancy (false-negative results) & & PA $(n=1)$, benign cyst $(n=1)$, mucocele $(n=1)$ \\
ACC & - & Oncocytoma $(n=1)$ \\
AciCC & - & WT $(n=1)$ \\
ANOS & BA $(n=2)$ & BA $(n=2)$, benign cyst $(n=1)$ \\
BADC & PA $(n=2)$ & PA $(n=7)$ \\
CPA & BA $(n=1)$, PA $(n=1)$ & PA $(n=1)$, benign lesion $(n=1)$ \\
EMC & - & PA $(n=2)$, benign cyst $(n=1)$, mucocele $(n=1)$ \\
MEC & - & Oncocytoma vs WT $(n=1)$ \\
OC & - & Benign lymphoid lesion $(n=1)$ \\
ML & & \\
Benign (false-positive results) & MEC $(n=1)$ & CPA $(n=1)$, LG malignancy $(n=1)$ \\
PA & - & ACC $(n=2)$ \\
ME &
\end{tabular}

CNB, core needle biopsy; FNAC, fine needle aspiration cytology; ACC, adenoid cystic carcinoma; PA, pleomorphic adenoma; AciCC, acinic cell carcinoma; ANOS, adenocarcinoma, not otherwise specified; WT, Warthin tumor; BADC, basal cell adenocarcinoma; BA, basal cell adenoma; CPA, carcinoma ex pleomorphic adenoma; EMC, epithelial-myoepithelial carcinoma; MEC, mucoepidermoid carcinoma; OC, oncocytic carcinoma; ML, malignant lymphoma; ME, myoepithelioma; LG, low grade. 


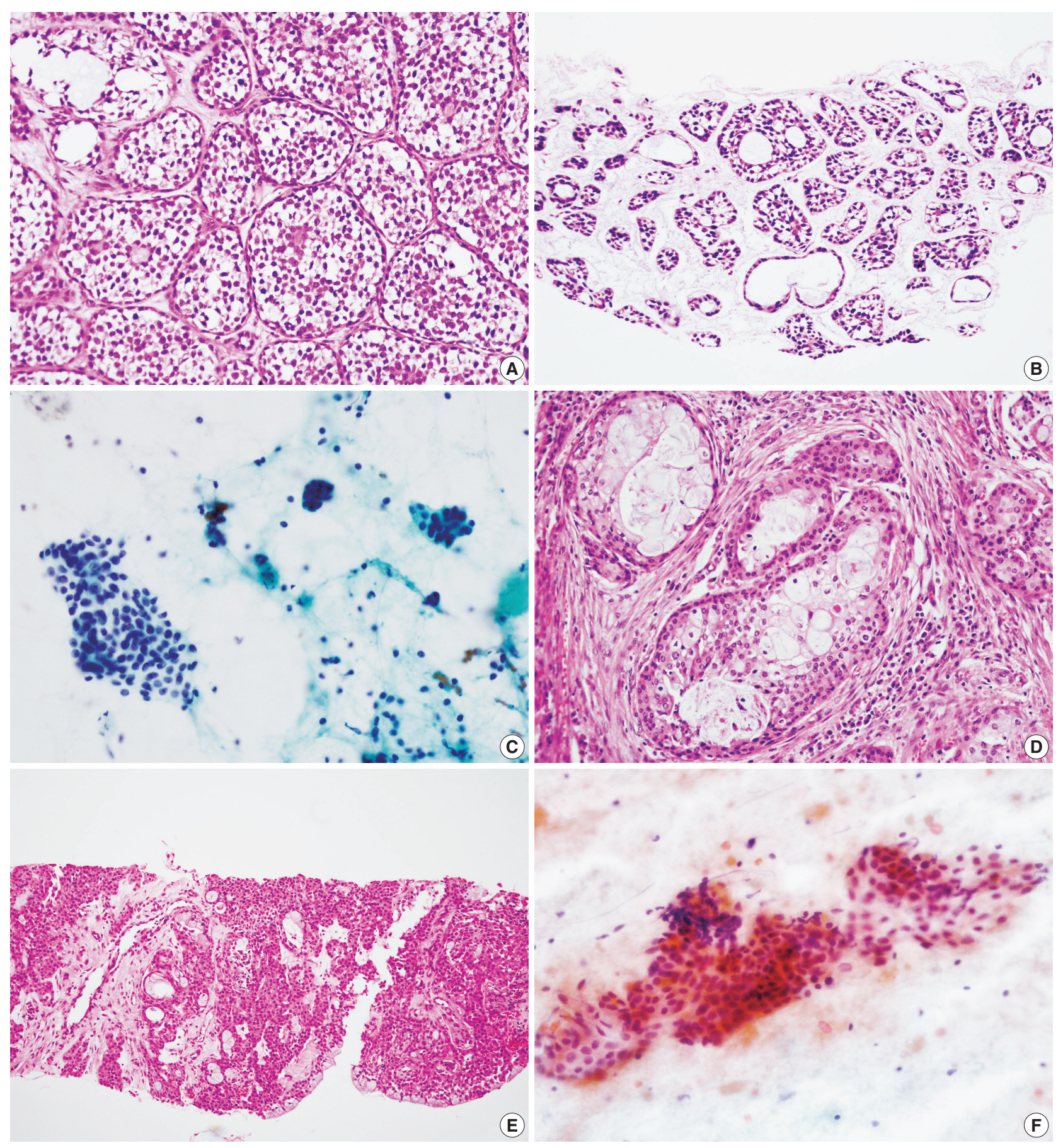

Fig. 1. Examples of low grade carcinomas diagnosed as false-negatives by fine needle aspiration cytology. (A) Adenoid cystic carcinoma in surgical specimens. (B) Core needle biopsy shows similar architectural findings. (C) Low cellularity and lack of obvious cellular atypia in fine needle aspiration cytology were interpreted as pleomorphic adenoma. (D) Mucoepidermoid carcinoma in surgical specimens. (E) Core needle biopsy shows intermediate and mucous cells. (F) Cystic background and presence of oncocytoid components in fine needle aspiration cytology led to the misdiagnosis of Warthin tumor.

neurogenic tumor. Tumor typing rates of benign tumors by $\mathrm{CNB}$ and FNAC were $91.8 \%$ and $80.5 \%$, respectively $(\mathrm{p}=.003)$. For malignant tumors, accurate tumor subtyping was achieved in
39 of 51 CNB cases (76.5\%), but in only 10 of 55 FNAC cases $(18.2 \%)(\mathrm{p}=.002)$. For a few special entities, both methods faced diagnostic difficulties. Since the diagnosis of basal cell adeno- 
Table 5. Accurate tumor subtyping rates of salivary gland tumors determined by preoperative CNB and FNAC

\begin{tabular}{|c|c|c|c|c|}
\hline $\begin{array}{l}\text { Histologic } \\
\text { diagnoses }\end{array}$ & & CNB & FNAC & $p$-value \\
\hline \multirow[t]{14}{*}{ Malignancy } & ACC & $9 / 9$ & $2 / 5$ & \\
\hline & AciCC & $3 / 3$ & $4 / 7$ & \\
\hline & ANOS & $2 / 2$ & $0 / 2$ & \\
\hline & BADC & $0 / 2$ & $0 / 4$ & \\
\hline & $\mathrm{CPA}$ & $2 / 5$ & $0 / 12$ & \\
\hline & CystADC & - & $0 / 1$ & \\
\hline & EMC & $0 / 2$ & $0 / 2$ & \\
\hline & MEC & $12 / 14$ & $2 / 6$ & \\
\hline & $\mathrm{OC}$ & - & $0 / 2$ & \\
\hline & $\mathrm{SCC}$ & $2 / 2$ & $0 / 1$ & \\
\hline & SDC & $7 / 10$ & $1 / 9$ & \\
\hline & $\mathrm{ML}$ & $1 / 1$ & $1 / 2$ & \\
\hline & RMS & $1 / 1$ & - & \\
\hline & UPS & - & $0 / 2$ & \\
\hline Subtotal & & 39/51 (76.5) & 10/55 (18.2) & .002 \\
\hline \multirow[t]{9}{*}{ Benign } & PA & $111 / 116$ & 170/189 & \\
\hline & WT & $31 / 31$ & $53 / 66$ & \\
\hline & $\mathrm{BA}$ & $12 / 16$ & $10 / 24$ & \\
\hline & LA & $0 / 1$ & - & \\
\hline & ME & $0 / 2$ & $2 / 6$ & \\
\hline & Oncocytoma & $1 / 2$ & $0 / 2$ & \\
\hline & NT & $2 / 3$ & $1 / 2$ & \\
\hline & $\mathrm{VT}$ & - & $0 / 3$ & \\
\hline & Lipoma & - & $0 / 1$ & \\
\hline Subtotal & & $157 / 171(91.8)$ & 236/293 (80.5) & .003 \\
\hline Total & & 196/222 (88.3) & $246 / 348(70.7)$ & $<.001$ \\
\hline
\end{tabular}

Values in parentheses are presented as percentage.

CNB, core needle biopsy; FNAC, fine needle aspiration cytology; ACC, adenoid cystic carcinoma; AciCC, acinic cell carcinoma; ANOS, adenocarcinoma, not otherwise specified; BADC, basal cell adenocarcinoma; CPA, carcinoma ex pleomorphic adenoma; CystADC, cystadenocarcinoma; EMC, epithelial-myoepithelial carcinoma; MEC, mucoepidermoid carcinoma; OC, oncocytic carcinoma; SCC, squamous cell carcinoma; SDC, salivary duct carcinoma; ML, malignant lymphoma; RMS, rhabdomyosarcoma; UPS, undifferentiated pleomorphic sarcoma; PA, pleomorphic adenoma; WT, Warthin tumor; BA, basal cell adenoma; LA, lymphadenoma; ME, myoepithelioma; NT, neurogenic tumor; VT, vascular tumor.

carcinoma and oncocytic carcinoma requires extracapsular invasion by definition, none of these cases could be diagnosed using either CNB or FNAC (Fig. 2). Similarly, the diagnosis of carcinoma ex pleomorphic adenoma was not possible without concomitant carcinoma and pleomorphic adenoma components, even by CNB. The diagnosis of epithelial-myoepithelial carcinoma was difficult by either method, most likely due to its resemblance to pleomorphic adenoma, its low-grade nature, and a low index of suspicion (Fig. 2).

\section{DISCUSSION}

In 1999, Buckland et al. ${ }^{13}$ introduced US-CNB using an 18gauge needle, instead of fine needle aspiration using a 23-gauge needle, to evaluate salivary gland lesions. They reported satisfactory results based on their experiences of diagnosing and treating parotid gland masses in up to 220 patients. ${ }^{14-17}$ The technique was soon adopted by other groups as well; small series of CNB results for salivary gland tumors have been reported from several countries, including the UK, Taiwan, Japan, and Germany. ${ }^{11,12,18-20}$

Our current study of $228 \mathrm{CNB}$ and 371 FNAC procedures demonstrates the superiority of $\mathrm{CNB}$ over FNAC for diagnosing salivary gland tumors in terms of adequacy ( $97.4 \%$ vs $93.8 \%)$, sensitivity $(88.2 \%$ vs $58.2 \%)$, specificity $(99.4 \%$ vs $98.6 \%)$, PPV (97.8\% vs $88.9 \%)$, NPV (96.6\% vs $92.6 \%$ ), and accurate tumor subtyping (88.3\% vs $70.7 \%$ ). Among these measures, differences in the sensitivity and tumor typing rate were statistically significant. These results are based on the histological confirmation of surgically treated cases. Although this type of design tends to lead to verification bias, ${ }^{21}$ we did not include follow-up cases because our aims were to compare the accuracy of the two tests for specific diagnoses. As a result, the sensitivities of both methods may have been overestimated due to verification bias. ${ }^{21}$ Even if the bias affected both methods, the sensitivity of $\mathrm{CNB}$ appears to be markedly improved, which can be attributed to the ability to recognize tumor structures by histological examination in CNB and not just cellular morphology alone as in FNAC.

The diversity and rarity of salivary gland carcinomas tend to provide diagnostic challenges for pathologists. Diagnosis of malignancy can be difficult when the cells in question pose no significant cytologic atypia. In addition, pathologists' experience and knowledge can affect the accuracy of FNAC. In our current study, no high-grade carcinomas, including salivary duct carcinoma and squamous cell carcinoma, were diagnosed as falsenegatives using FNAC; however, low-grade carcinomas, including adenoid cystic carcinoma, acinic cell carcinoma, mucoepidermoid carcinoma, epithelial-myoepithelial carcinoma, and adenocarcinoma not otherwise specified, were occasionally misinterpreted as benign lesions. The PPV and NPV, which are not affected by verification bias, were also higher in CNB than in FNAC, though the differences were not statistically significant.

The difficulties of diagnosing basal cell adenocarcinoma, oncocytic carcinoma, and carcinoma ex pleomorphic adenoma apply to not only FNAC, but also to CNB when invasive and/or malignant foci are not sampled. For example, we misinterpreted two epithelial-myoepithelial carcinomas as pleomorphic adenoma in one and basal cell adenoma in the other, and one pleomorphic adenoma as mucoepidermoid carcinoma in CNB. Sali- 

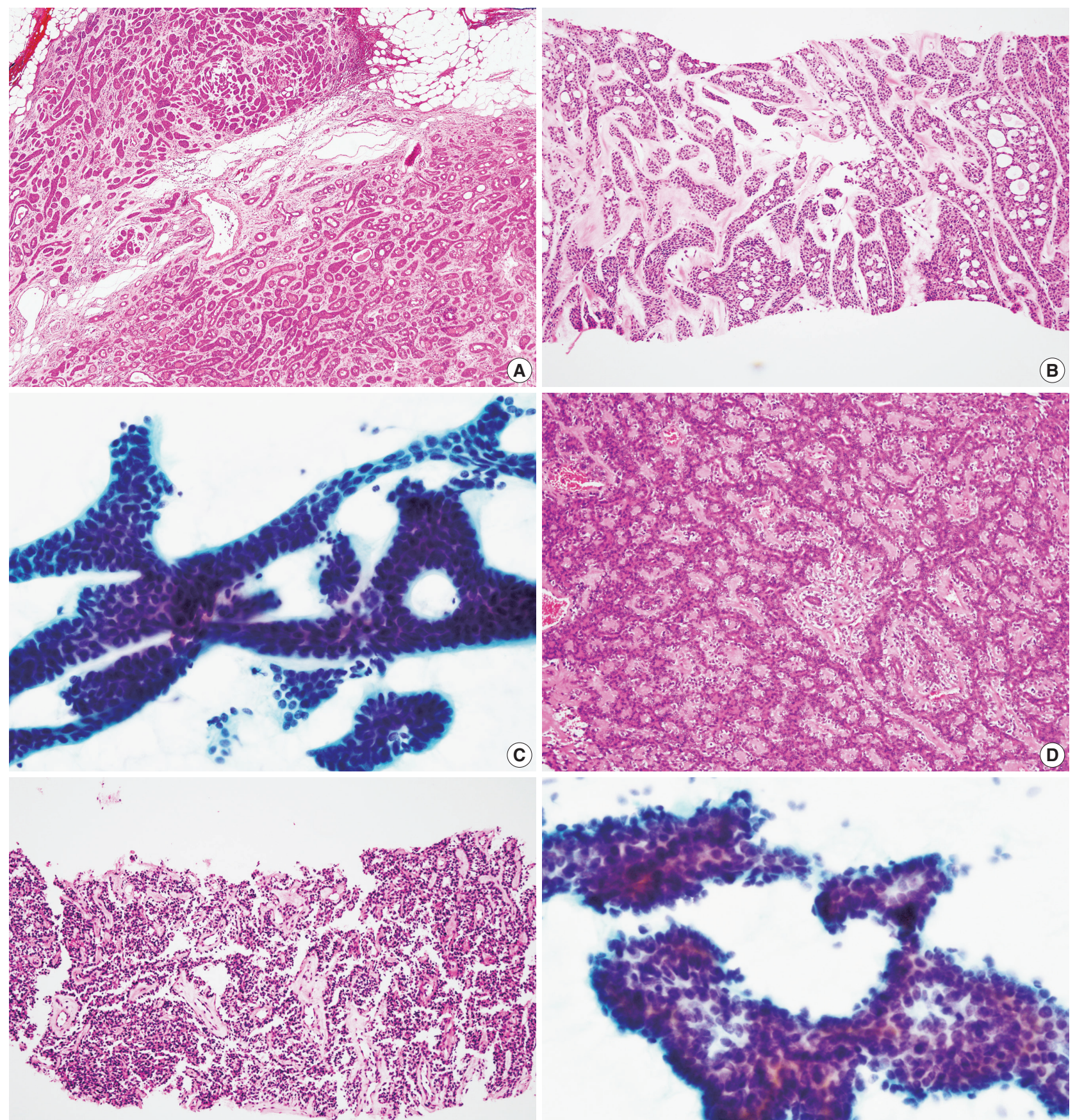

(E)

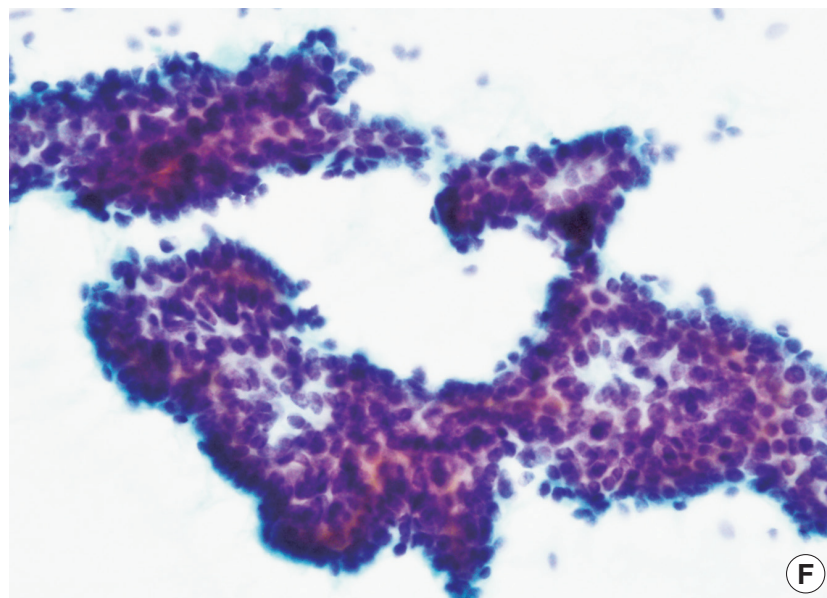

Fig. 2. Difficult samples for both core needle biopsy and fine needle aspiration. (A) Surgical specimen of basal cell adenocarcinoma shows extracapsular invasion which cannot be confirmed in core needle biopsy (B) or fine needle aspiration cytology (C). (D) Epithelial-myoepithelial structures of epithelial-myoepithelial carcinoma can be mistaken for those of pleomorphic adenoma in both core needle biopsy (E) and fine needle aspiration cytology $(F)$, because of the lack of obvious cellular atypia.

vary gland tumors are diverse and also analogous with specific architectural patterns such as epithelial-myoepithelial structures which are present in various benign and malignant tumors. Interpreting a limited number of cores can be difficult, even for experienced pathologists. Nonetheless, accurate tumor subtyping rates were generally higher for CNB than for FNAC (88.3\% vs $70.7 \%$ ). In particular, malignant tumors were more often accurately classified using CNB than FNAC (76.5\% vs $18.2 \%$ ) in 
comparison to the benign tumors ( $91.8 \%$ vs $80.5 \%$ ). Both highand low-grade carcinomas could be more specifically diagnosed by CNB than by FNAC.

Some clinicians prefer FNAC because it has technical advantages such as simplicity of the procedure, safety, cost-effectiveness, and the lack of need for ultrasound assistance. However, the $\mathrm{CNB}$ procedure is generally well tolerated under local anesthesia, and the actual complication rate of $\mathrm{CNB}$ appears to be far less than expected. The major complications of salivary gland biopsy include facial nerve injury and tumor seeding along the biopsy track. However, experienced radiologists can avoid facial nerve injury by tracing the main intraparotid vessels or the parotid duct, which can be easily identified on ultrasound. ${ }^{14,18} \mathrm{Tu}-$ mor seeding was once considered a significant complication when performing large needle biopsy on cancers, and the needle diameter and number of passes are assumed to be related to this risk. ${ }^{22}$ However, such evidence is lacking in the case of salivary gland tumors. Two cases of tumor seeding following needle biopsy of the salivary gland using 14-16-gauge needles have been previously reported, but a few reports of tumor seeding following FNAC have also been reported more recently. ${ }^{23,24}$ However low the risk, some authors have suggested surgical removal of the biopsy track at the time of surgery. ${ }^{12,25}$

No studies on the use of 18 -gauge CNB to assess the salivary glands, including our present series, have reported these major complications. The minor complications that have been reported following salivary gland CNB include subclinical hematoma, ${ }^{11,12,14-16,18,20}$ temporary facial weakness after local anesthesia, ${ }^{11}$ and the formation of salivary fistulas. ${ }^{17}$ Fistula developed after post-biopsy acute parotitis and did not present with tumor seeding. ${ }^{17}$ Increased awareness of this rare complication would help provide better patient care and follow-up.

In conclusion, $\mathrm{CNB}$ is an accurate and safe method for diagnosing salivary gland lesions, and provides significant superiority in accurate tumor subtyping in comparison to FNAC. We recommend $\mathrm{CNB}$ as the primary diagnostic tool for preoperatively evaluating salivary gland masses, especially when malignancy is suspected.

\section{Conflicts of Interest}

No potential conflict of interest relevant to this article was reported.

\section{REFERENCES}

1. Schmidt RL, Hall BJ, Wilson AR, Layfield LJ. A systematic review and meta-analysis of the diagnostic accuracy of fine-needle aspiration cytology for parotid gland lesions. Am J Clin Pathol 2011; 136: 45-59.

2. Kim BY, Hyeon J, Ryu G, et al. Diagnostic accuracy of fine needle aspiration cytology for high-grade salivary gland tumors. Ann Surg Oncol 2013; 20: 2380-7.

3. Tryggvason G, Gailey MP, Hulstein SL, et al. Accuracy of fine-needle aspiration and imaging in the preoperative workup of salivary gland mass lesions treated surgically. Laryngoscope 2013; 123: 15863.

4. Nguansangiam S, Jesdapatarakul S, Dhanarak N, Sosrisakorn K. Accuracy of fine needle aspiration cytology of salivary gland lesions: routine diagnostic experience in Bangkok, Thailand. Asian Pac J Cancer Prev 2012; 13: 1583-8.

5. Huang YT, Jung SM, Ko SF, et al. Diagnostic efficacy of ultrasonography-guided fine needle aspiration biopsy in evaluating salivary gland malignancy. Chang Gung Med J 2012; 35: 62-9.

6. Kechagias N, Ntomouchtsis A, Valeri R, et al. Fine-needle aspiration cytology of salivary gland tumours: a 10-year retrospective analysis. Oral Maxillofac Surg 2012; 16: 35-40.

7. Piccioni LO, Fabiano B, Gemma M, Sarandria D, Bussi M. Fine-needle aspiration cytology in the diagnosis of parotid lesions. Acta Otorhinolaryngol Ital 2011; 31: 1-4.

8. Cho HW, Kim J, Choi J, et al. Sonographically guided fine-needle aspiration biopsy of major salivary gland masses: a review of 245 cases. AJR Am J Roentgenol 2011; 196: 1160-3.

9. Schmidt RL, Hall BJ, Layfield LJ. A systematic review and meta-analysis of the diagnostic accuracy of ultrasound-guided core needle biopsy for salivary gland lesions. Am J Clin Pathol 2011; 136: 516-26.

10. Novoa E, Gurtler N, Arnoux A, Kraft M. Role of ultrasound-guided core-needle biopsy in the assessment of head and neck lesions: a meta-analysis and systematic review of the literature. Head Neck 2012; 34: 1497-503.

11. Pfeiffer J, Ridder GJ. Diagnostic value of ultrasound-guided core needle biopsy in patients with salivary gland masses. Int J Oral Maxillofac Surg 2012; 41: 437-43.

12. Huang YC, Wu CT, Lin G, Chuang WY, Yeow KM, Wan YL. Comparison of ultrasonographically guided fine-needle aspiration and core needle biopsy in the diagnosis of parotid masses. J Clin Ultrasound 2012; 40: 189-94.

13. Buckland JR, Manjaly G, Violaris N, Howlett DC. Ultrasound-guided cutting-needle biopsy of the parotid gland. J Laryngol Otol 1999; 113: 988-92.

14. Kesse KW, Manjaly G, Violaris N, Howlett DC. Ultrasound-guided biopsy in the evaluation of focal lesions and diffuse swelling of the parotid gland. Br J Oral Maxillofac Surg 2002; 40: 384-8. 
15. Howlett DC, Menezes LJ, Lewis K, Moody AB, Violaris N, Williams MD. Sonographically guided core biopsy of a parotid mass. AJR Am J Roentgenol 2007; 188: 223-7.

16. Breeze J, Andi A, Williams MD, Howlett DC. The use of fine needle core biopsy under ultrasound guidance in the diagnosis of a parotid mass. Br J Oral Maxillofac Surg 2009; 47: 78-9.

17. Sriskandan N, Manjaly G, Howlett DC. Re: Breeze J, Andi A, Williams MD, Howlett DC. The use of fine needle core biopsy under ultrasound guidance in the diagnosis of a parotid mass [Br. J. Oral Maxillofac. Surg. 2009;47(1):78-9]. Br J Oral Maxillofac Surg 2009; 47: 493-4.

18. Wan YL, Chan SC, Chen YL, et al. Ultrasonography-guided coreneedle biopsy of parotid gland masses. AJNR Am J Neuroradiol 2004; 25: 1608-12.

19. Taki S, Yamamoto T, Kawai A, Terahata S, Kinuya K, Tonami H. Sonographically guided core biopsy of the salivary gland masses: safety and efficacy. Clin Imaging 2005; 29: 189-94.
20. Pratap R, Qayyum A, Ahmed N, Jani P, Berman LH. Ultrasoundguided core needle biopsy of parotid gland swellings. J Laryngol Otol 2009; 123: 449-52.

21. Schmidt RL, Jedrzkiewicz JD, Allred RJ, Matsuoka S, Witt BL. Verification bias in diagnostic accuracy studies for fine- and core needle biopsy of salivary gland lesions in otolaryngology journals: a systematic review and analysis. Head Neck 2014; 36: 1654-61.

22. Roussel F, Nouvet G. Evaluation of large-needle biopsy for the diagnosis of cancer. Acta Cytol 1995; 39: 449-52.

23. Witt BL, Schmidt RL. Ultrasound-guided core needle biopsy of salivary gland lesions: a systematic review and meta-analysis. Laryngoscope 2014; 124: 695-700.

24. Douville NJ, Bradford CR. Comparison of ultrasound-guided core biopsy versus fine-needle aspiration biopsy in the evaluation of salivary gland lesions. Head Neck 2013; 35: 1657-61.

25. Howlett DC. Diagnosing a parotid lump: fine needle aspiration cytology or core biopsy? Br J Radiol 2006; 79: 295-7. 